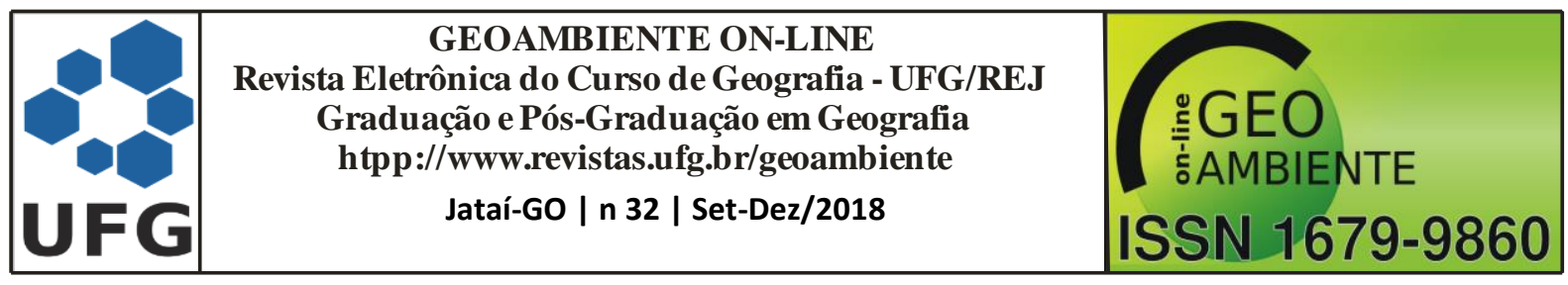

\title{
DIAGNÓSTICO SOCIOAMBIENTAL DA COMUNIDADE DO CRESPO, MANAUS/AMAZONAS
}

Gabriela Mendonça da Silva ${ }^{1}$, Mhayra Ysllanna Torres Rocha ${ }^{2}$, Adoréa Rebello da Cunha

\section{Albuquerque $^{3}$}

(1- Universidade Federal do Amazonas, Geógrafa, gabrielamendoncadasilva@gmail.com; 2Universidade Federal do Amazonas, Geógrafa, ys.llanna@gmail.com, 3 - Universidade Federal do Amazonas, Doutora, Docente do Curso de Geografia, adorea27@ yahoo.com )

Resumo: Este trabalho tem por objetivo apresentar um diagnóstico socioambiental da comunidade do Crespo utilizando-se dos dados de saneamento (distribuição de água, drenagem de esgoto e limpeza urbana). O bairro do Crespo situa-se na zona Sul da cidade de Manaus (AM) na microbacia do Igarapé do Quarenta. Para a obtenção dos dados, utilizou-se o método de pesquisa participativa por meio da aplicação de questionários mediante anuência da comunidade, e em caráter coletivo. Os resultados indicaram que o principal problema enfrentado na área de pesquisa, foi à ausência de saneamento básico acarretando inundações, alagamento.

Palavras-chave: Saneamento; Infraestrutura; Inundações; Meio Ambiente.

\section{SOCIO-ENVIRONMENTAL DIAGNOSIS OF THE CRESPO COMMUNITY,}

\section{MANAUS-AMAZONAS}

Abstract: The objective of this work is to present a socio-environmental diagnosis of the Crespo community using sanitation data (water distribution, sewage drainage and urban cleaning). The Crespo neighborhood is located in the southern part of the city of Manaus (AM) in the Igarapé do Quarenta microbasin. To obtain the data, the participatory research method was used through the application of questionnaires through community consent, and on a collective basis. The results indicated that the main problem faced in the research area was the absence of basic sanitation causing flooding, flooding.

Keywords: Sanitation; Infrastructure; floods; environment.

Artigo recebido para publicação em 08 de Agosto de 2017

Artigo aprovado para publicação em 14 de Setembro de 2018 


\begin{tabular}{|c|c|c|}
\hline & $\begin{array}{c}\text { GEOAMBIENTE ON-LINE } \\
\text { Revista Eletrônica do Curso de Geografia - UFG/REJ } \\
\text { Graduação e Pós-Graduação em Geografia } \\
\text { htpp://www.revistas.ufg.br/geoambiente } \\
\text { Jataí-Go | n } 32 \text { | Set-Dez/2018 }\end{array}$ & $\begin{array}{c}\text { : GEO } \\
\text { G.AMBIENTE } \\
\text { G }\end{array}$ \\
\hline
\end{tabular}

\section{DIAGNÓSTICO SOCIOAMBIENTAL DE LA COMUNIDAD DEL CRESPO.}

\section{MANAUS / AMAZONAS}

Resumen: Este trabajo tiene por objetivo presentar un diagnóstico socioambiental de la comunidad del Crespo utilizando los datos de saneamiento (distribución de agua, drenaje de aguas residuales y limpieza urbana). El barrio del Crespo se sitúa en la zona sur de la ciudad de Manaus (AM) en la microbacia del Igarapé del Cuarenta. Para la obtención de los datos, se utilizó el método de investigación participativa por medio de la aplicación de cuestionarios mediante anuencia de la comunidad, y en carácter colectivo. Los resultados indicaron que el principal problema enfrentado en el área de investigación, fue a la ausencia de saneamiento básico acarreando inundaciones, inundación.

Palabra clave: Saneamiento; Infraestructura; Inundaciones; Medio ambiente

\section{INTRODUÇÃO}

O ser humano possui a necessidade de transformar o meio que o cerca, no entanto essa necessidade gera perturbações ao equilíbrio natural. É no meio natural, que o homem dispõe de recursos para satisfazer suas necessidades, essas ações negativas perante ao meio provocam problemas sociais como doenças, inundações e poluição.

A construção de uma infraestrutura urbana adequada às necessidades da população se apresenta como uma complexa tarefa para seus gestores públicos, em países como o Brasil, onde $91,5 \%$ dos municípios nacionais foram classificados neste item, com os níveis ruins e muito ruins de bem-estar urbano conforme os dados expressos pelo Índice de Bem-Estar Urbano dos Municípios Brasileiros (RIBEIRO e RIBEIRO, 2016).

A cidade de Manaus apresenta o relevo entrecortado por vários cursos hídricos e, em decorrência do seu processo de expansão e urbanização, muitas pessoas passaram a habitar as margens de igarapés ${ }^{1}$. Por conta dessas ocupações, os rios da cidade, têm sido utilizados pela população como um sistema de esgoto, o que se caracteriza como um grave problema urbano por consistir em riscos, tanto para a saúde dos indivíduos que residem próximos a estes locais, como pelos impactos causados ao meio natural.

\footnotetext{
${ }^{1}$ Igarapé é um termo regional para designar um canal fluvial.
} 


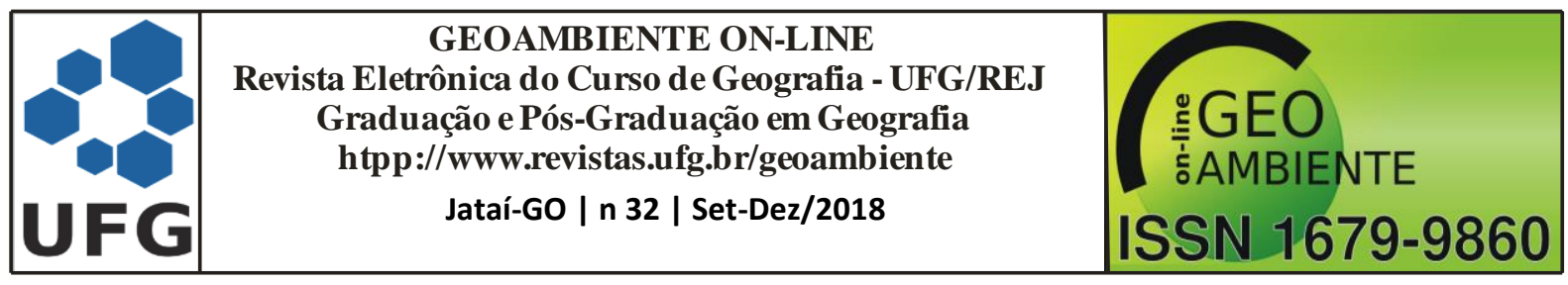

De acordo com Macena (2016), a cidade de Manaus apresenta suscetibilidade a eventos de risco em decorrência de suas peculiaridades geológico-geomorfológicas, potencializadas pela fragilidade do poder decisório no planejamento, e na gestão de novas áreas para habitação.

O diagnóstico socioambiental realizado na comunidade do Crespo teve como principal objetivo identificar os principais problemas ambientais urbanos através das temáticas saneamento básico e as necessidades da população ali residente e suas eventuais causalidades, haja vista os processos de ocupação que ocorreram durante a formação socioespacial desse setor da bacia.

\section{METODOLOGIA}

Para a elaboração do diagnóstico socioambiental do bairro do Crespo, foi utilizado o método de pesquisa social com participação coletiva e aplicação de questionários com forma de perguntas mistas. Buscou-se primeiramente estabelecer contato com a comunidade por intermédio do presidente do bairro, o qual atuou como facilitador da realização do levantamento de dados. No entanto, no decorrer da aplicação dos questionários muitos moradores não apresentaram disponibilidade a responder, sendo esta a dificuldade encontrada na pesquisa.

Foram aplicados 15 questionários estruturados nas Ruas Nova Esperança, Paz, São Pedro, União, Luzitânia e Carlos, sendo uma amostragem aleatória simples, de maneira que os questionários foram aplicados predominantemente nas áreas de maior proximidade com o igarapé do Quarenta, uma vez que, se trata de um local onde são observados impactos socioambientais decorrentes da falta de estrutura adequada, visto que o intuito era de observar os impactos ambientais decorrentes correlacionados com os problemas sociais.

O questionário (Figura 1) aplicado na comunidade visou à investigação dos itens de infraestrutura urbana sobre saneamento básico como distribuição de água, drenagem de esgoto e limpeza urbana. Os dados coletados foram sistematizados e tabulados para a elaboração de gráficos e tabelas no software Excel, como também mapas de localização no programa Qgis. Além disso, utilizou-se a ferramenta Google Earth para a verificação da extensão e elevação da microbacia. 


\begin{tabular}{|c|c|c|}
\hline & $\begin{array}{c}\text { GEOAMBIENTE ON-LINE } \\
\text { Revista Eletrônica do Curso de Geografia - UFG/REJ } \\
\text { Graduação e Pós-Graduação em Geografia } \\
\text { htpp://www.revistas.ufg.br/geoambiente } \\
\text { Jataí-Go | n } 32 \text { | Set-Dez/2018 }\end{array}$ & $\begin{array}{c}\text { : GEO } \\
\text { G.AMBIENTE } \\
\text { G }\end{array}$ \\
\hline
\end{tabular}

Figura 1. Modelo de questionário aplicado.

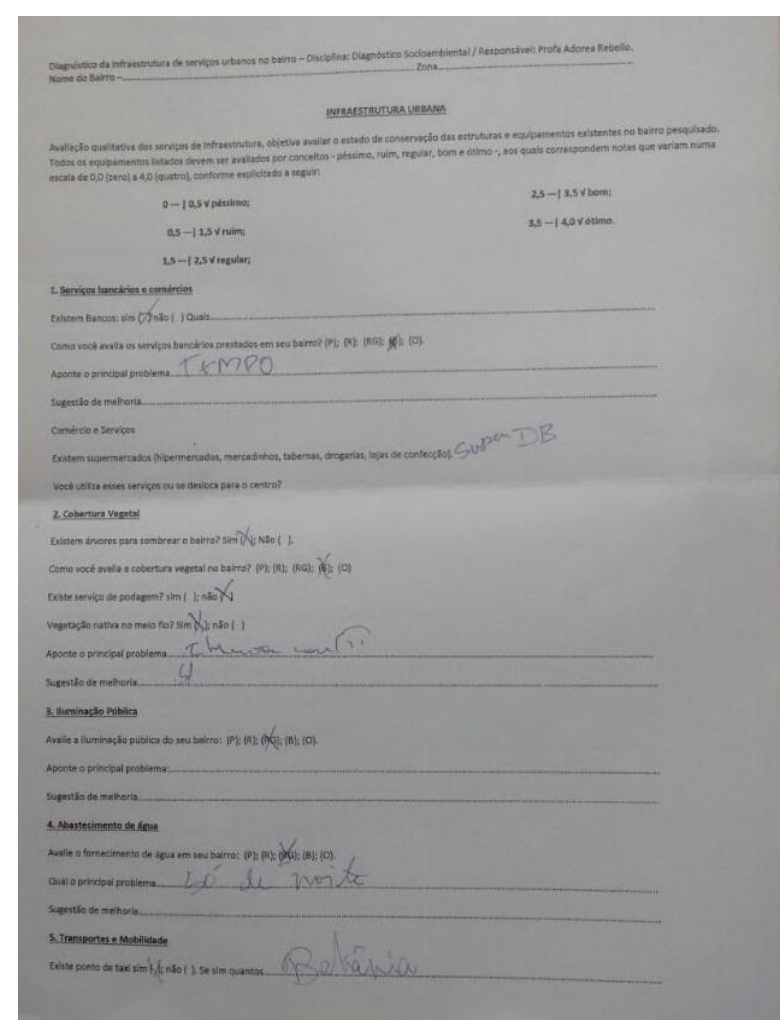

Fonte: os autores, 2017.

\section{Área de estudo}

A cidade de Manaus está geologicamente situada na Bacia Sedimentar Fanerozóica correspondente à formação Alter do Chão, composta por arenitos finos a médios, a camada de arenito foi denominado de Arenito Manaus, sendo caracterizada por apresentar arenitos e siltitos silicificados avermelhados e estruturas sedimentares preservadas (SILVA, 2005). De acordo com o Mapa Geomorfológico do Instituto Brasileiro de Geografia e Estatística (2010), a geomorfologia do sítio urbano de Manaus corresponde ao Planalto do Uatumã-Jari, a comunidade do Crespo localiza-se às margens do Igarapé do Quarenta possui formas de relevo que não ultrapassam 105 metros de altitude com vales alargado na forma de "U", modeladamente e altamente dissecado (GONCALVES, PAES e MOLINARI, 2014).

A área de estudo está situada na microbacia do Igarapé do Quarenta (Figura 2), apresenta 88 canais de primeira ordem com um percentual de nascente equivalente a 53, 9\% de sua rede de drenagem (MACENA, 2016). A bacia do igarapé se estende desde a zona Leste da cidade abrangendo os bairros Zumbi, Armando Mendes, Coroado e Distrito Industrial I e 


\begin{tabular}{|c|c|c|}
\hline & $\begin{array}{c}\text { GEOAMBIENTE ON-LINE } \\
\text { Revista Eletrônica do Curso de Geografia - UFG/REJ } \\
\text { Graduação e Pós-Graduação em Geografia } \\
\text { htpp://www.revistas.ufg.br/geoambiente } \\
\text { Jataí-Go | n } 32 \text { | Set-Dez/2018 }\end{array}$ & $\begin{array}{c}\text { : GEO } \\
\text { G.AMBIENTE } \\
\text { G }\end{array}$ \\
\hline
\end{tabular}

II, a zona Sul com os bairros Raiz, Japiim, Crespo, Betânia, Morro da Liberdade, Santa Luzia e Educandos, onde deságua no rio Negro. A microbacia do igarapé do Quarenta é de $4^{\circ}$ ordem, sendo um canal retilinizado, que apresenta áreas sem cobertura vegetal e área com fragmentos de cobertura vegetal, onde as áreas sem cobertura vegetal propiciam assoreamento e a entrada de lixo no canal.

Figura 2. Mapa de localização do bairro do Crespo.
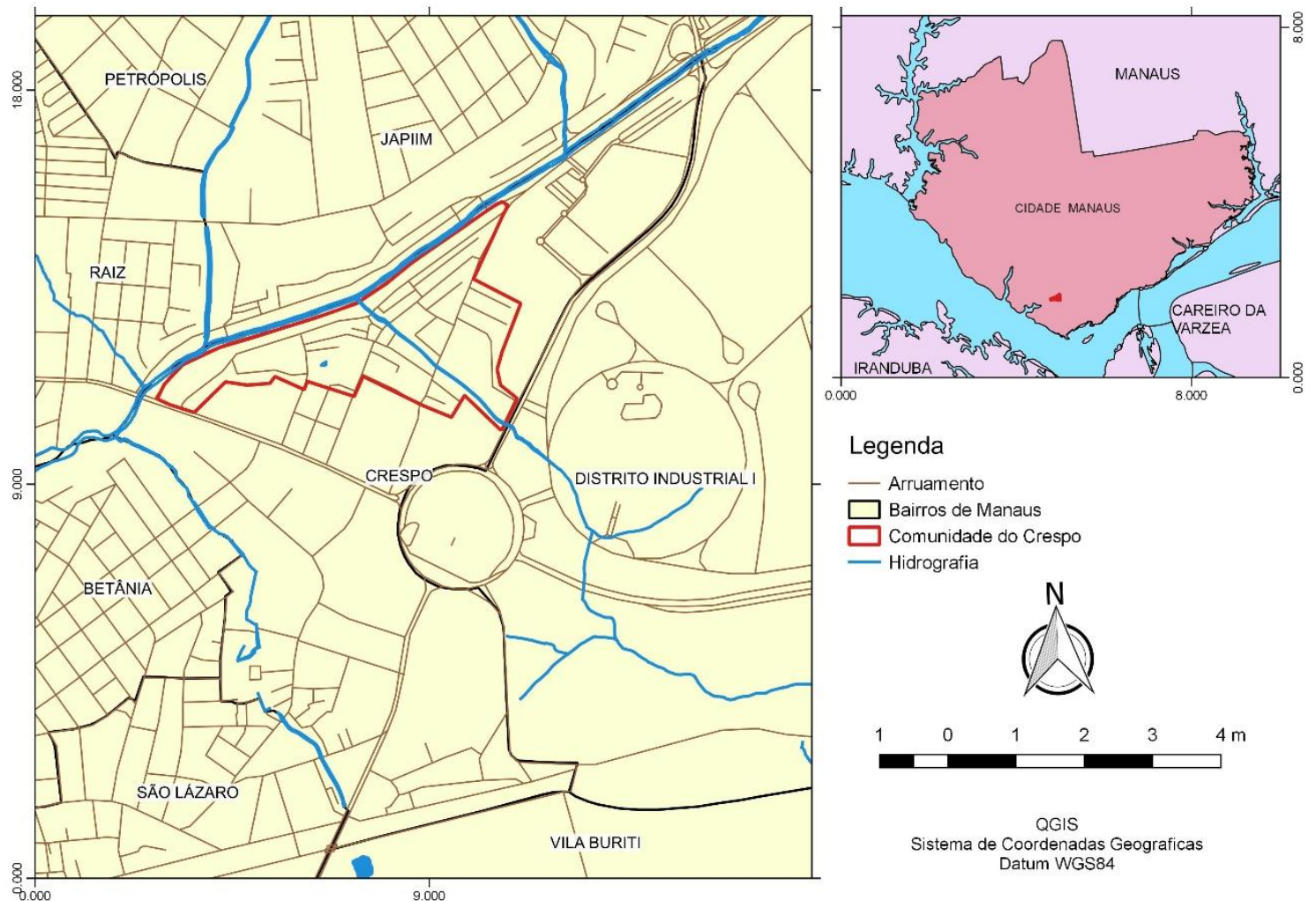

Legenda

- Arruamento

$\square$ Bairros de Manaus

$\square$ Comunidade do Crespo

- Hidrografia
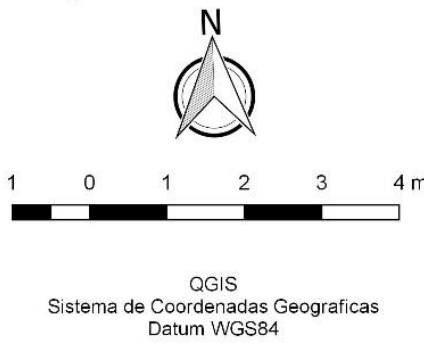

Organização: os autores

Segundo Vieira (2008), a cidade de Manaus apresenta duas classes de solos que podem ser mais facilmente evidenciadas, Latossolos e Espodossolos. A classe Latossolo compreende solos minerais, onde apresentam uma sequência de horizontes A, B e C (MAIA e MARMOS 2010).

O clima é do tipo Equatorial caracterizado por precipitações anuais de 1.500 a 4.000 milímetros (TROPPMAIR, 2012). As temperaturas extremas em Manaus chegam a $27,7^{\circ} \mathrm{C}$ em setembro e $25,8^{\circ} \mathrm{C}$ em abril com aumento de chuvas no verão, e temperatura média anual de $26,5^{\circ} \mathrm{C}$, tendo uma umidade relativa elevada durante o ano. 


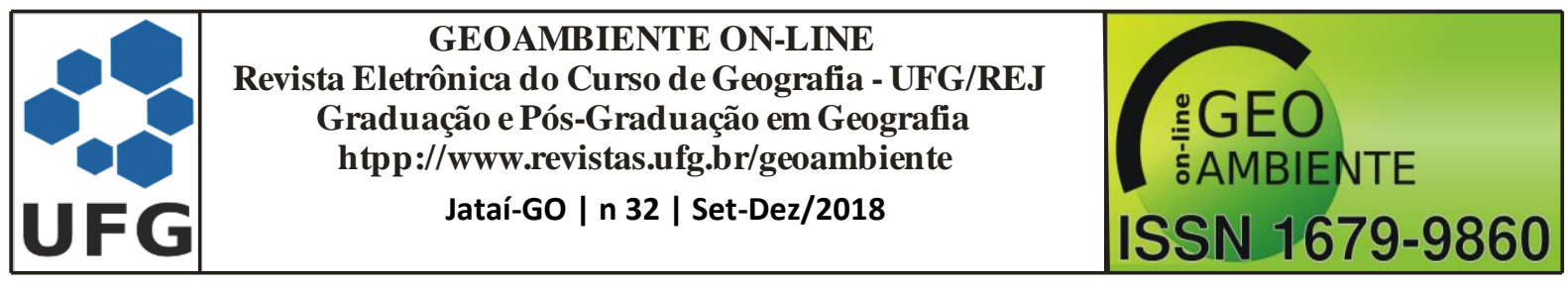

No que diz respeito à ocorrência de vegetação, é possível encontrar os tipos: Floresta Ombrófila Densa, Floresta Densa Tropical Úmida (Floresta Equatorial ou Floresta Pluvial Tropical Latifoliada). Devido ao intenso processo de ocupação desordenada ocorrente na cidade, são recorrentes margens desflorestadas, o que afeta diretamente os cursos hídricos, sendo os altos valores de temperatura relacionados à falta da mata ciliar.

No igarapé do Quarenta, ainda se encontra vegetação típica de mata primária, no entanto, ao longo de seu curso é possível notar mata ciliar totalmente modificada e acúmulo de resíduos sólidos nas margens. No trecho próximo à área de estudo, a vegetação encontra-se totalmente modificada, e em função da implantação do PROSAMIM (Programa Social e Ambiental dos Igarapés de Manaus) que entre os objetivos visa à restituição da vegetação nativa no perímetro legal da Área de Preservação Permanente (APP), foram plantadas mudas de árvores nas margens do igarapé.

A comunidade em questão está situada numa Área de Proteção Permanente (APP), conforme a Lei de $n^{\circ} 12.651 / 2012$, a APP é área protegida, coberta ou não por vegetação nativa, com a função ambiental de preservar os recursos hídricos, a paisagem, a estabilidade geológica e a biodiversidade, facilitar o fluxo gênico de fauna e flora, proteger o solo e assegurar o bem-estar das populações humanas.

A lei ainda prevê APP para faixas marginais de qualquer curso d'água natural perene e intermitente, excluídos os efêmeros, desde a borda da calha do leito regular. Segundo Oliveira e Rebello (2009) o igarapé em estudo possui em média 8 a 8,5 metros de largura, sendo assim, a APP é no mínimo de 30 metros de largura.

O igarapé do Quarenta é, atingido por diferentes graus de poluição principalmente em suas nascentes, apenas quatro dessas, encontram-se sem contaminação de lixo doméstico ou resíduos industriais, e estão localizadas em áreas protegidas ambientalmente, as demais apresentam altos níveis de contaminação, principalmente por esgoto doméstico e pelos detritos industriais despejados das fábricas do Distrito Industrial. Embora não exista um consenso entre os pesquisadores de bacias hidrográficas admite-se que as indústrias instaladas no Distrito Industrial sejam os principais agentes poluidores acrescidos de atividades antrópicas dos habitantes das margens do igarapé do Quarenta. (SCHERER e MENDES FILHO, 2004). 


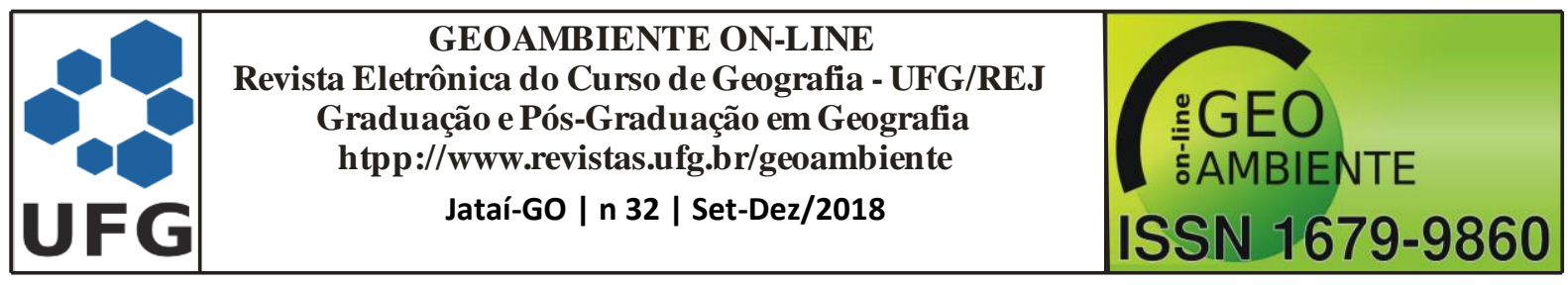

Segundo os dados censitários do IBGE, o município de Manaus possui uma população estimada em 2016 de 2.094.391 habitantes numa extensão territorial de 11.401,092 km². Manaus é a capital do Amazonas, sendo a principal metrópole da Amazônia Ocidental, além disso, é a sede da Região Metropolitana de Manaus. O bairro Crespo é situado na zona Sul de Manaus e de acordo com a Lei $\mathrm{n}^{\circ}$ 1.401, de 14 de Janeiro de 2010, bairro Crespo compreende aproximadamente 110 hectares consistindo o Igarapé da Lagoa Verde com o Igarapé do Quarenta. Segundo o censo demográfico de 2010 do Instituto Brasileiro de Geografia e Estatísticas, o bairro Crespo possuia uma densidade demográfica de 15.451 habitantes, sendo 7.622 homens e 7.829 mulheres.

Souza e Oliveira (2003) afirmam que as ocupações na área do Igarapé do Quarenta referem-se ao início da expansão da malha urbana de Manaus, onde servia como ancoradouro de embarcações no período das enchentes que aos poucos se transformou em alternativa de local de moradia para as populações de baixa renda, e com a criação da Zona Franca de Manaus (ZFM) em 1957 pela Lei de número 3.173, o processo de urbanização na cidade de Manaus como em todo o estado se intensificou a partir dos fluxos migratórios, em consequência ocorreu o surgimento das ocupações entorno do igarapé do Quarenta.

\section{RESULTADOS E DISCUSSÃO}

De acordo com os dados do Índice de Bem-estar Urbano (IBEU), Manaus exibe a posição de $4654^{\circ}$ no ranking, no que diz respeito à infraestrutura e drenagem fluvial, a cidade é a segunda pior das regiões metropolitanas do país. Conforme o Sistema Nacional de Informações sobre Saneamento (SNIS) em 2016 a cidade de Manaus era a $5^{\circ}$ entre as maiores cidade do pais em indicadores de saneamento básico, onde somente $23,8 \%$ do esgoto passava por um tratamento. Além disso, a cidade estava entre as 20 piores do ranking do saneamento em 2017 (TRATA BRASIL, 2018).

$\mathrm{Na}$ aplicação dos questionários, 10 dos moradores do bairro consideram péssimo o serviço de saneamento (distribuição de água, drenagem de esgoto e limpeza urbana), 3 declararam ruim e 2 julgaram como regular as condições de saneamento (Figura 3). As condições de infraestrutura urbana na comunidade do Crespo no que diz respeito à drenagem e saneamento constituem um reflexo dos problemas urbanos não somente da cidade de Manaus, como de diversas cidades do Brasil. 


\begin{tabular}{|c|c|c|}
\hline & $\begin{array}{c}\text { GEOAMBIENTE ON-LINE } \\
\text { Revista Eletrônica do Curso de Geografia - UFG/REJ } \\
\text { Graduação e Pós-Graduação em Geografia } \\
\text { htpp://www.revistas.ufg.br/geoambiente } \\
\text { Jataí-Go | n } 32 \text { | Set-Dez/2018 }\end{array}$ & $\begin{array}{c}\text { : GEO } \\
\text { G.AMBIENTE } \\
\text { G }\end{array}$ \\
\hline
\end{tabular}

Figura 3. Grau de satisfação dos moradores da comunidade.

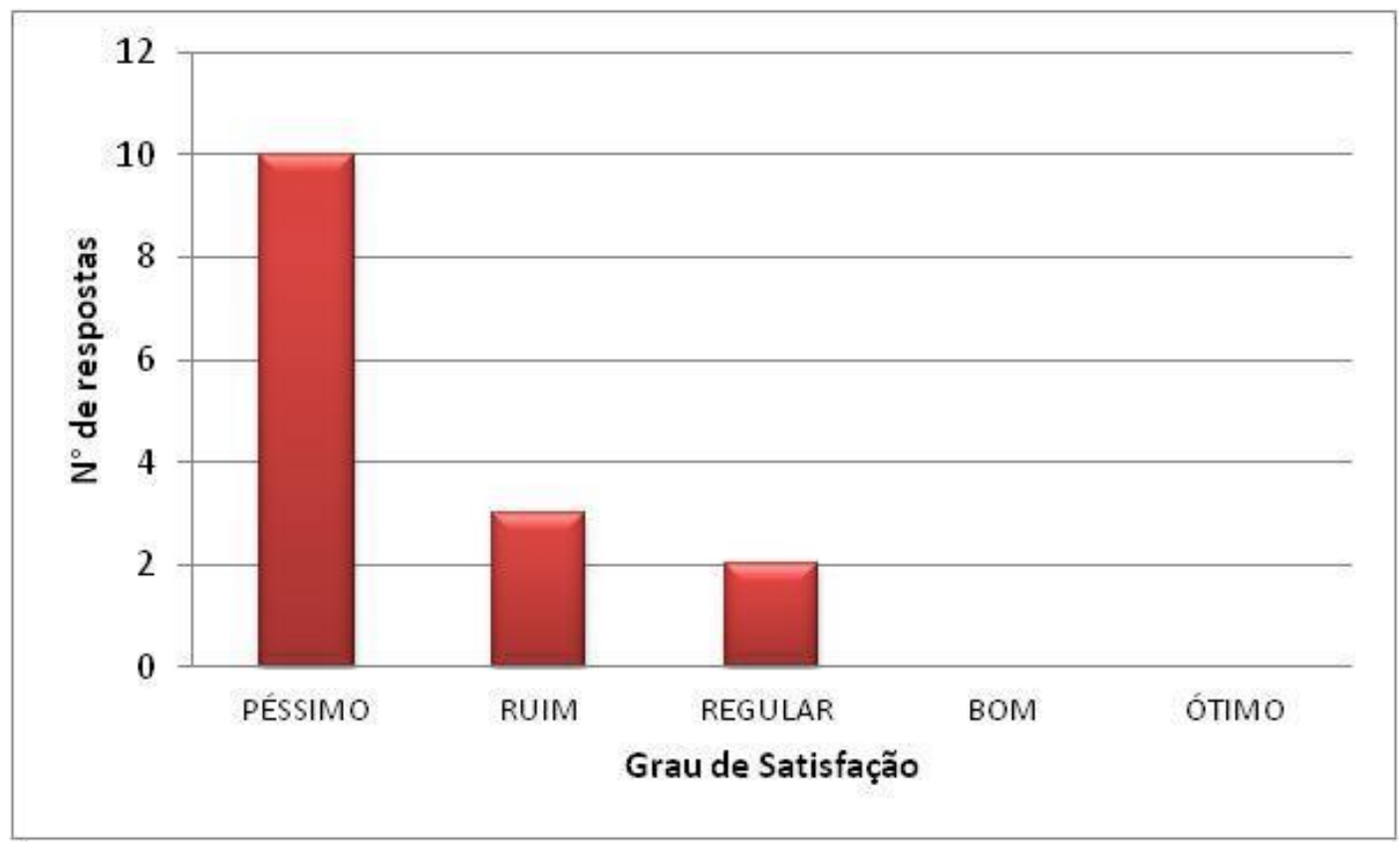

As péssimas condições de saneamento constituíram a principal reclamação dos moradores, visto que, a comunidade está situada no ponto de inundação do igarapé no qual durante o período de chuvas na cidade transborda e invade as ruas e residências.

$\mathrm{Na}$ figura $04 \mathrm{~A}$ e $\mathrm{C}$ se exibe o alagamento ocorrido em janeiro de 2016 na comunidade do Crespo, na figura B se apresenta o transbordamento do canal. Além disso, o canal sofreu alterações devido atividades antrópicas no trecho entre as avenidas Silves e Rodrigo Otávio, ocasionando a formação de banco de dejeto devido à passagem do Prosamim nos anos de 2010 a 2014. Com a reurbanização proposta pelo Prosamim, o canal teve seu curso modificado o que acarretou em diversos problemas ambientais e em consequência sociais. $\mathrm{O}$ trecho passou a sofrer com o assoreamento, que consiste em bancos areias no canal devido à baixa velocidade de escoamento da água (Figura 5), diminuindo o armazenamento da água no canal provocando inundações.

O Prosamim consiste no Programa Social e Ambiental dos Igarapés de Manaus como objetivo de promover o saneamento, desassoreamento dos canais hidrográficos e contribuir para a melhoria de vida dos habitantes que residem nas bacias hidrográficas da cidade (PROSAMIM, 2004). Conforme Silva (2018), um dos objetivos do Prosamim é solucionar problemas ambientais, ao contrário disso, os problemas de ordem ambiental se intensificaram. 


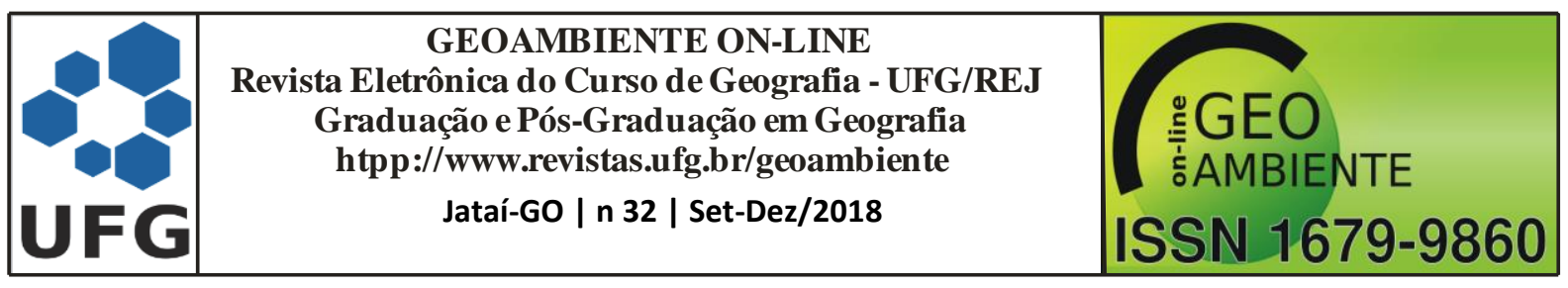

Figura 04. Alagação e InundaçõesGON ocorridas em Janeiro de 2017. Alagação na Rua São Pedro; B) Inundação na Rua Paranavai e C) Alameida São Francisco.

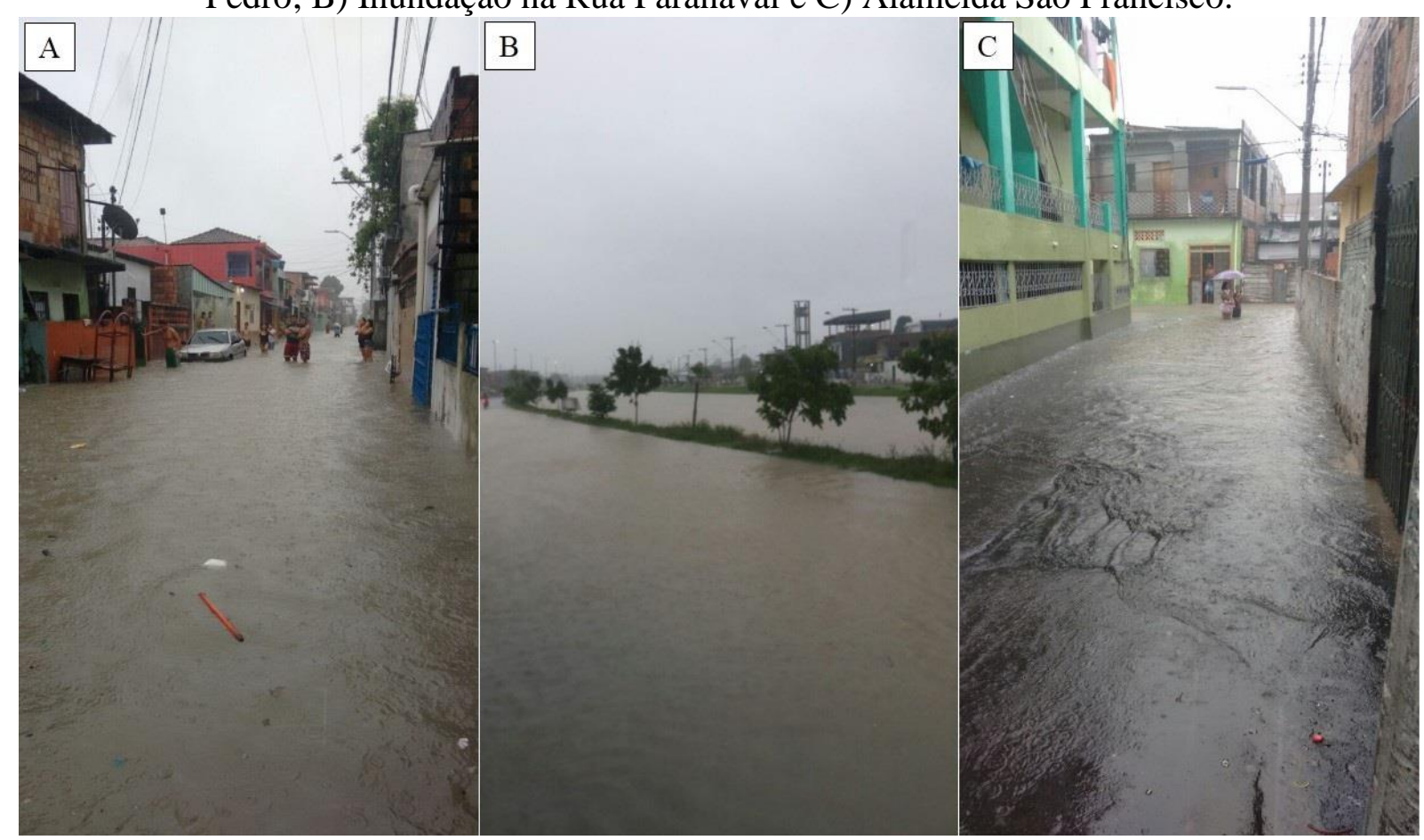

Foto: Autores

Figura 5. Formação de bancos de areia devido o descarte de lixo e drenagem de esgoto para o

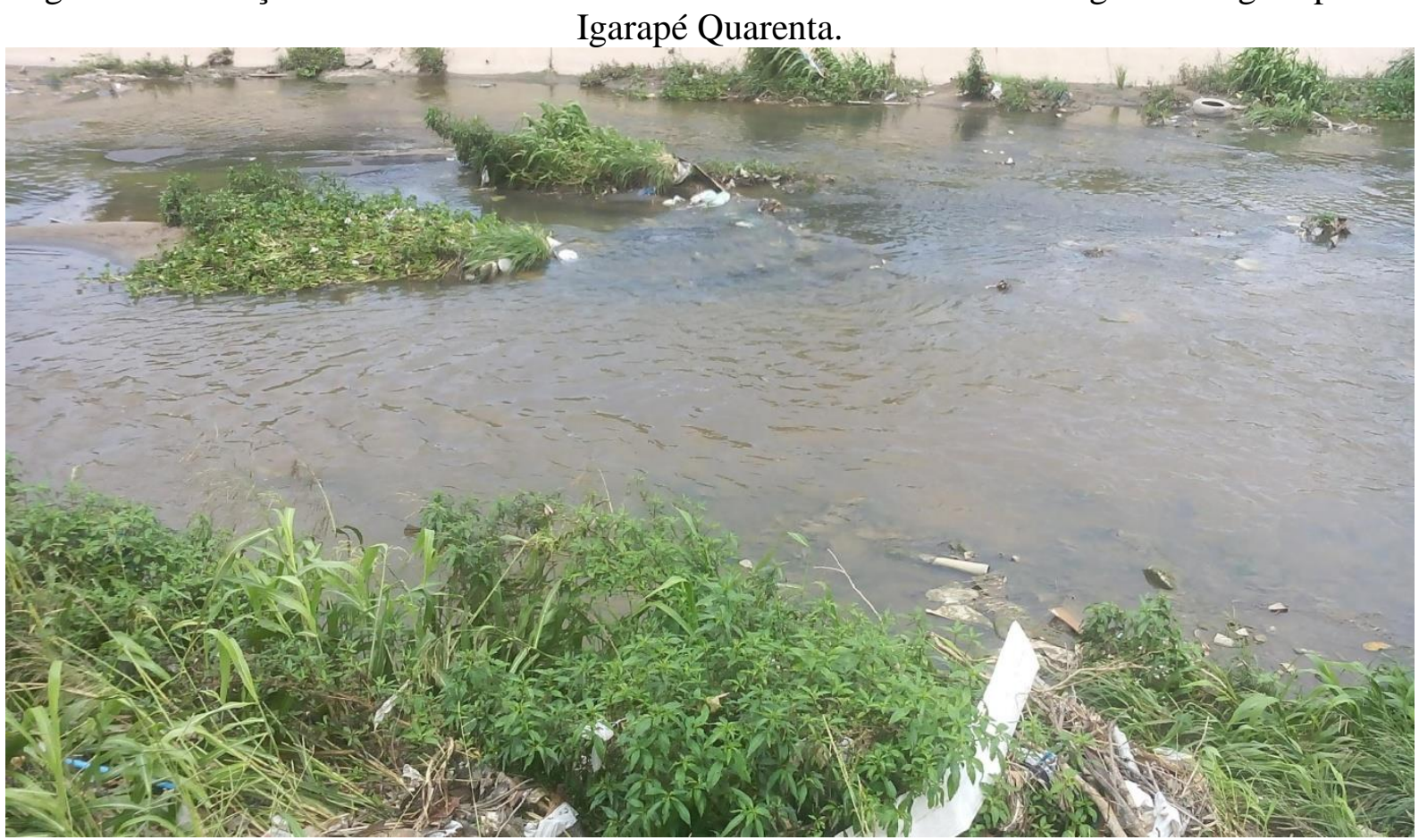

Foto: Autores 


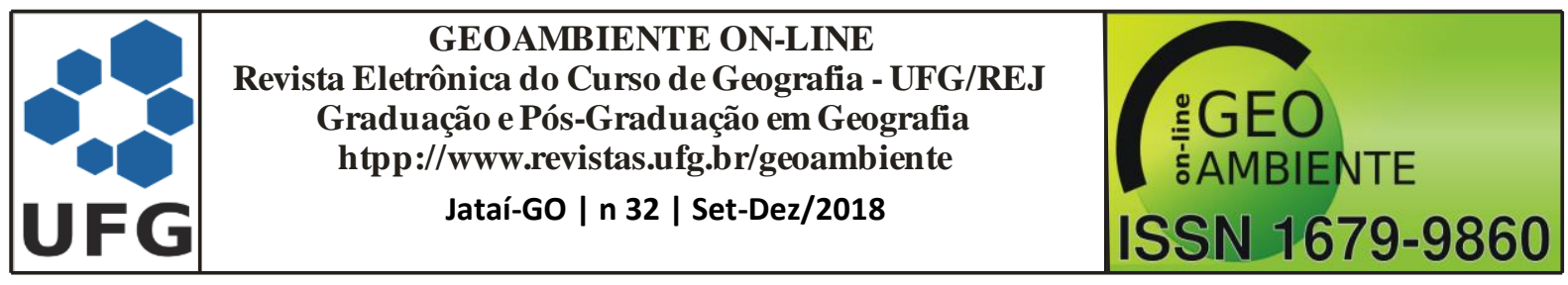

A cidade Manaus possui 60 Estações do Tratamento de Esgoto (ETE) e 51 elevatórios distribuídos pela cidade, no entanto, são evidentes as deficiências nesse tipo de serviço, uma vez que, em muitos bairros a drenagem do sistema de esgoto sanitário se dá diretamente para os igarapés. A exemplo, tem-se o caso da comunidade do Crespo, que não possui uma ETE e os esgotos são direcionados para o Igarapé do Quarenta provocando risco socioambiental.

Conforme Oliveira e Rebello (2009) esse processo é consequência das ocupações desordenadas que alteram a dinâmica hidrológica do igarapé do Quarenta acarretando inundações no período do verão, onde ocorrem chuvas intensas. O igarapé tornou-se um esgoto a céu aberto no período da chuva, os resíduos sólidos depositados pelos próprios moradores provocam o assoreamento do leito do curso d'água, contribuindo com a propagação de diversas formas de doenças (OLIVEIRA e REBELLO, 2009).

O sistema de coleta de lixo pela prefeitura ocorre com frequência no bairro 4 vezes por semana, sendo coletado todos os resíduos domésticos. No entanto, o local é atingido com alagamentos frequentes em decorrência dos bueiros abertos, onde há acúmulo de lixo proveniente das ruas, causando obstrução durante as chuvas, impossibilitando o escoamento da água e gerando inundações.

Conforme os parâmetros da Lei $n^{\circ} 12.651 / 2012$, o igarapé do Quarenta deveria possuir uma área de 30m de APP (BRASIL, 2010), no entanto tais critérios não são considerados e sequer cumpridos na Lei, uma vez que essa área é ocupada por residências, comércios e igrejas, sendo o igarapé a divisão de duas vias de trânsito (Figura 6). 


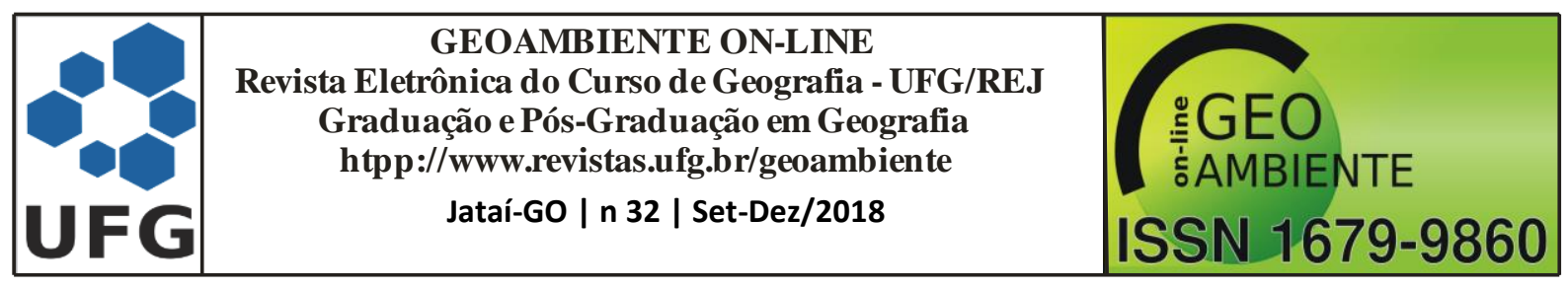

Figura 6. Trecho canalizado do Igarapé do Quarenta.

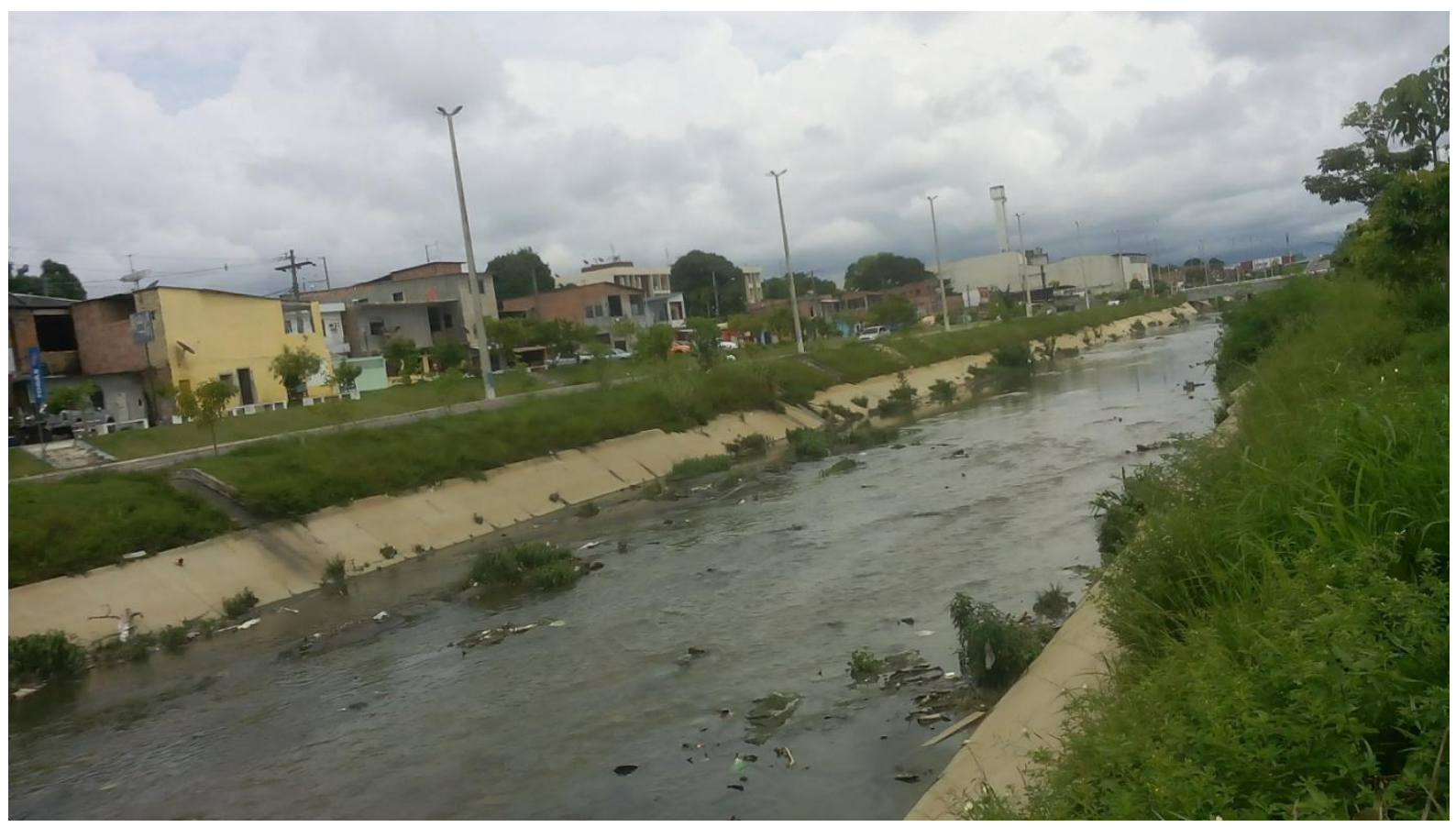

Foto: Autores

\section{CONSIDERAÇÕES FINAIS}

No que diz respeito aos problemas socioambientais de grande parte das cidades brasileiras, verificam-se transtornos alarmantes que afetam a qualidade de vida de toda população, principalmente dos indivíduos economicamente vulneráveis.

A cidade de Manaus experimentou um período de rápida expansão na área urbana, o que desencadeou graves problemas ambientais devido ao crescimento demográfico, com o surgimento de habitações irregulares, causados pela ausência de planejamento territorial sistemático. A partir do levantamento dos dados, foi possível verificar a fragilidade em saneamento urbano de Manaus na região do Crespo, tendo como principais afetados os residentes dos bairros formados a partir de ocupações irregulares, provenientes da rápida expansão da cidade.

Nas margens do igarapé do Quarenta, na comunidade do Crespo, foram verificados problemas de ordem física, no que diz respeito à poluição do canal fluvial, como apontava Melo et al. (2005), provenientes das indústrias, residências e comércios na área circundante, sendo grande o transtorno, por conta das inundações que ocorrem também em função da ação do PROSAMIM que ao tornar retilíneo o igarapé, reduz sua capacidade de vazão natural, e 


\begin{tabular}{|c|c|c|}
\hline & $\begin{array}{c}\text { GEOAMBIENTE ON-LINE } \\
\text { Revista Eletrônica do Curso de Geografia - UFG/REJ } \\
\text { Graduação e Pós-Graduação em Geografia } \\
\text { htpp://www.revistas.ufg.br/geoambiente } \\
\text { Jataí-Go | n } 32 \text { | Set-Dez/2018 }\end{array}$ & $\begin{array}{c}\text { :GEO } \\
\text { ISAMBIENTE } \\
\text { ISSN 1679-9860 }\end{array}$ \\
\hline
\end{tabular}

pelo o estreitamento da margem, ocasiona alagamentos durante as fortes chuvas características da cidade.

Mediante as observações feitas e os questionários aplicados, relacionados aos relatos dos moradores é possível considerar os impactos sofridos pela população, tendo as inundações como principal causador de danos, que se deve às intervenções antrópicas no igarapé, o que se deu desde a ocupação das margens do mesmo, e perdura mediante o descarte incorreto dos resíduos urbanos e industriais.

Em vista dos problemas apresentados, é importante ressaltar o papel da administração dos municípios para o desenvolvimento das cidades, sendo de responsabilidade do poder público, a criação e efetivação de políticas públicas que contemplem a realidade e necessidade de cada localidade e a participação da comunidade com o intuito de estabelecer a qualidade de vida da população.

\section{REFERÊNCIAS BIBLIOGRÁFICAS}

BRASIL. Lei no 1.401, de 14 de janeiro de 2010. Diário Oficial de Manaus. Manaus, AM, ano XI, Edição 2366, 14 jan. 2010.

INSTITUTO BRASILEIRO DE GEOGRAFIA E ESTATÍSTICA. Cidades. Disponível em: <http://cidades.ibge.gov.br/xtras/perfil.php?codmun=130260>. Acesso em: 20 dez. de 2016

Estado do Amazonas Geomorfologia, 2010. Disponível em: <http://geoftp.ibge.gov.br/informacoes_ambientais/geomorfologia/mapas/unidades_da_federa cao/am_geomorfologia.pdf > Acesso em: abril de 2016.

GONCALVES, V.; PAES, K. e MOLINARI, D. Caracterização da área de preservação permanente da Bacia do Igarapé do Quarenta- Manaus (Amazonas). In: Revista Geonorte, Edição Especial 4, v. 10, n. 1, 2014. p. 223- 228.

MACENA, L. S.L. Áreas de riscos nas bacias hidrográficas urbanizadas de Manaus, 2016. 262f. Dissertação (Mestrado em Geografia) Universidade Federal do Amazonas, Amazonas, Manaus, 2016.

MAIA, M. A. M. e. MARMOS, J. L. Geodiversidade do Estado do Amazonas. Manaus: CPRM, 2010. 275p. 


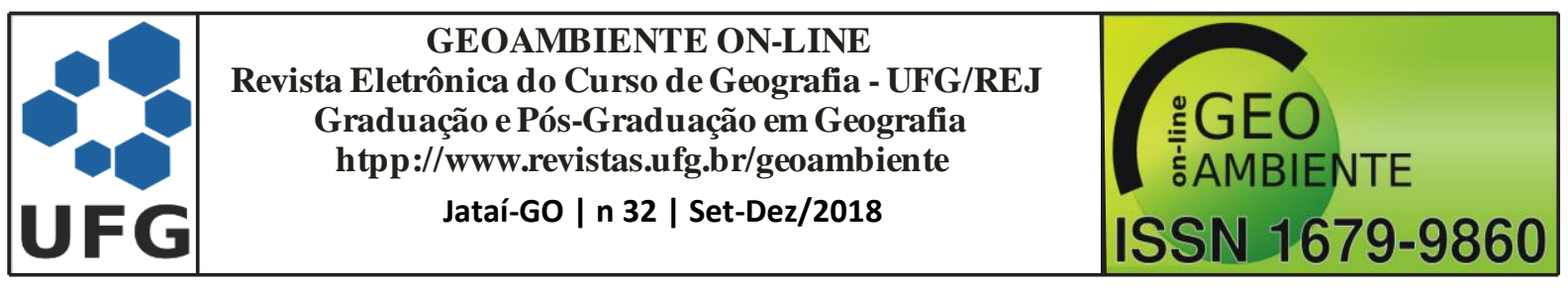

MELO, E. G. F.; SILVA, M. S. R. e MIRANDA, S. A. F. Influência antrópica sobre águas de igarapés na cidade de Manaus- Amazonas. In: Caminhos de Geografia, out/2005. p. 40-47.

OLIVEIRA, E. G. e REBELLO, A. Planejamento ambiental em bacias hidrográficas: um estudo preliminar de indicadores socioambientais na microbacia do quarenta (Manaus-Am) In: Simpósio Brasileiro de Geografia Física Aplicada na UFV, Anais, XIII, 2009, Minas Gerais. p.1-19.

PROSASMIM- Programa Social e Ambiental dos Igarapés de Manaus. Relatório de Impacto Ambiental, Governo do Estado do Amazonas, 2004.

RIBEIRO, L. C. Q. e RIBEIRO, M. G. IBEU municipal Índice de bem-estar urbano dos municípios brasileiros, Rio de Janeiro: Observatório das Metrópoles, 2016. 117p.

SARGES, R.R.; SILVA, T.M. e RICCOMINI, Cláudio. Caracterização do relevo da região de Manaus, Amazônia Central. In: Revista Brasileira de Geomorfologia, v. 12, n 1, 2011. p. 95-104.

SCHERER, E. e MENDES FILHO, I. Injustiça ambiental em Manaus. In: Encontro Associação Nacional de Pós Graduação e Pesquisa em Ambiente e Sociedade,2. Anais, Indaiatuba: ANPPAS, 2004. Disponível em: <http://www.anppas.org.br/encontro_anual/encontro2/GT/GT17/gt17_elenise.pdf>. Acesso em: 20 dez. 2016. p. 1-11.

SILVA, G. M. Dinâmica do uso da terra na paisagem na microbacia do Igarapé do Quarenta, Manaus-AM. In: Revista Geonorte, v. 3 n. 33, 2018. p. 81-94. Disponível em: <http://www.periodicos.ufam.edu.br/revista-geonorte/article/view/4494>. Acesso em: dez de 2018.

SILVA, C. L. Análise da tectônica cenozóico da região de Manaus e adjacências. 282p. Tese (Doutorado no Programa de Pós- Graduação em Geociências) - Universidade Estadual Paulista. São Paulo, 2005.

SISTEMA NACIONAL DE INFORMAÇÕES SOBRE SANEAMENTO. Agrupamento dinâmico de indicadores e informações por ano de referência. Disponível em: <http://app3.cidades.gov.br/serieHistorica/municipio/index>. Acesso em: dez. de 2017 


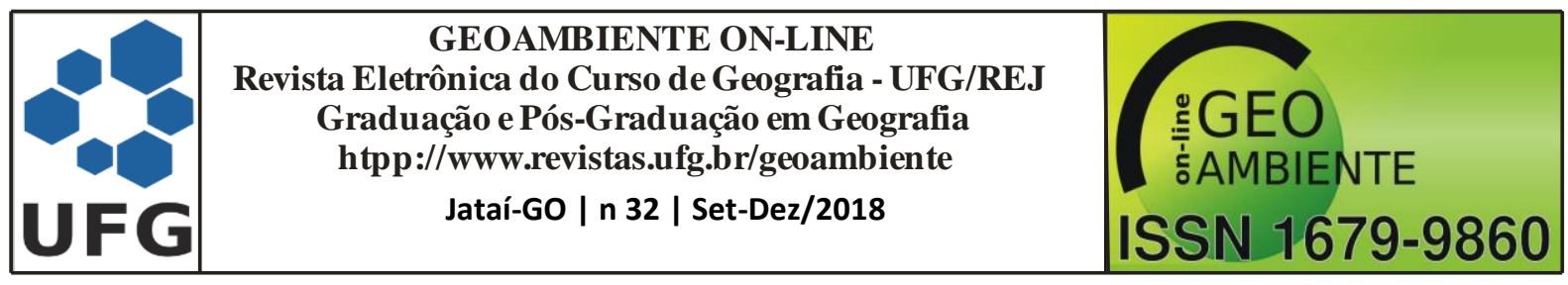

SOUZA, N. D. e OLIVEIRA, J. A. de. O espaço urbano e a produção de moradia em áreas inundáveis na cidade de Manaus: o igarapé do Quarenta. In: OLIVEIRA, J. A. de; ALECRIM, J. D. e GASNIER, T. R. J. Cidade de Manaus: visões interdisciplinares, Editora: EDUA, Manaus, 2003. p. 81-116.

TRATA BRASIL, Relatório ranking do saneamento instituto trata brasil, 2018. Disponível em <http://www.tratabrasil.org.br/images/estudos/itb/ranking-2018/realatoriocompleto.pdf>. Acesso em: dez. de 2017.

TROPPMAIR, H. Biogeografia e meio ambiente. 9 ed. Rio de Janeiro: Technical Books, 2012. 281p.

VIEIRA, A. F. G. Desenvolvimento de distribuição de voçorocas em Manaus (AM): principais fatores controladores e impactos urbanos -ambientais, 303f. Tese (Doutorado em Geografia): Departamento de Geografia. UFSC, 2008. 